\title{
Pengaruh Metode Bermain terhadap Motivasi Siswa pada Materi Servis Atas Pembelajaran Bola Voli Sekolah Menegah Pertama
}

Tias Lucky Darmawan $^{a *}$, Nana Suryana Nasution ${ }^{\mathrm{b}}$, Setio Nugroho ${ }^{\mathrm{c}}$

${ }^{a}$ Universitas Singaperbangsa Karawang, Indonesia

Correspondence: 1610631070154@student.unsika.ac.id

Received: 21 Jul 2020 Accepted: 09 Feb 2021 Published: 30 Apr 2021

\begin{abstract}
This study aims to examine the effect of playing methods on students' motivation on service material in junior high school volleyball learning. This study used an experimental method with the design of One Group Pretest Posttest Design. The population used was all students of class VIII totaling six classes of 215 students, taken using cluster random sampling technique into one class of 36 students. The data collection technique that is used in this research was a questionnaire through validity and reliability tests. The data analysis technique used the $\mathrm{z}$ test, through the prerequisite normality test with pretest and posttest data with the Sig. 0.253 and 0.261> 0.05 , these results indicate that the data is normally distributed. The $z$ test results show the value of Sig. 2 tailed 0,000 . Therefore $0.000<0.05$, it can be concluded that there is an effect of the playing method on student motivation in service material for junior high school volleyball learning.
\end{abstract}

Keywords: floating service; motivation; playing methods.

\begin{abstract}
Abstrak
Penelitian ini bertujuan untuk mengkaji pengaruh metode bermain terhadap motivasi siswa pada materi servis atas pembelajaran bola voli sekolah menengah pertama. Penelitian ini menggunakan metode eksperimen dengan desain One Grup Pretest Posttest Design. Populasi yang digunakan adalah seluruh siswa kelas VIII berjumlah enam kelas sebanyak 215 siswa, diambil dengan sampel menggunakan teknik cluster random sampling menjadi satu kelas sebanyak 36 siswa. Teknik pengumpulan data penelitian menggunakan angket melalui uji validitas dan reliabilitas. Teknik analisis data menggunakan uji z, melalui prasyarat uji normalitas dengan data pretest dan posttest nilai Sig. 0,253 dan 0,261 >0,05 hasil tersebut menunjukan hasil data berdistribusi normal. Hasil uji z menunjukan nilai Sig. 2 tailed 0,000. Oleh karena 0,000 $<0,05$ maka dapat disimpulkan bahwa terdapat pengaruh metode bermain terhadap motivasi siswa pada materi servis atas pembelajaran bola voli sekolah menengah pertama.
\end{abstract}

Kata kunci: servis atas; motivasi; metode bermain.

\section{Pendahuluan}

Pendidikan jasmani merupakan pembelajaran yang memiliki kelebihan tersendiri karena memberikan kontribusi secara menyeluruh yaitu afektif, kognitif dan psikomotorik, salah satu aspek penting dalam bidang pendidikan adalah pendidkan jasmani. Maka dari itu tujuan pendidikan jasmani harus dapat dicapai. Menurut (Rahayu, 2016) tujuan pendidikan jasmani ialah meningkatkan berbagai aspek yaitu aspek kebugaran, kesehatan, jasmani, sikap kritis, kesetabilan emosional, sikap sosial, pemahaman dan prilaku melalui kegiatan olahraga dan jasmani. Menurut (Pahliwandari, 2016) pendidikan jasmani itu sendiri untuk meningkatkan kemampuan psikomotor, kognitif dan afektif dengan melibatkan 
pelakunya menjadi sarana dalam pelaksanaannya. Bahkan menurut (Efendi, 2017) pendidikan jasmani bertujuan guna mencapai progress jasmani, kesegaran jasmani, kesehatan, kemampuan, kecerdasan, peningkatan pola pikir, serta kepribadian yang bahagia dalam hal pembentukan individu yang berkualitas. Pada dasarnya tujuan pendidikan jasmani itu untuk mengembangkan sikap, pikiran, serta gerak. Jika tiga hal tersebut dapat meningkat maka dapat dinyatakan pendidikan jasmani berjalan sebagai mana mestinya. Menurut (Rahayu, 2016) ruang lingkup pendidikan jasmani meliputi aspekaspek berikut: 1) Permainan dan olahraga, 2) Aktivitas pengembangan 3) Aktivitas senam, 4) Aktivitas ritmik, 5) Aktivitas air, 6) Pendidikan luar kelas, 7) Kesehatan. Melalui ketujuh aktivitas tersebut terdapat pembelajaran bola voli salah satunya.

(Hanggara, 2018) menyatakan bahwa bola voli adalah olahraga yang dimainkan oleh dua regu saling berlawanan dengan aturan melewatkan bola diatas net bertujuan memperoleh jatuhnya bola ke area lawan agar mendapatkan kemenangan pada saat bermain. Menurut (La'I \& Haluti, 2018) berbagai teknik dasar dalam permainan bola voli seperti teknik servis, servis merupakan gerakan memukul bola langsung ke area lawan oleh seorang pemain yang dilakukan dari daerah servis. Servis itu terbagi menjadi dua yaitu servis bawah, dan servis atas.

Menurut (Syaleh, 2017) servis atas merupakan servis yang sulit diterima lawan karena pergerakan bola yang sangat liar saat setelah dipukul, cepatnya bola juga tidak terkendalikan, bola melayang tak tentun arahnya sehingga arah bola sulit ditebak. Menurut (Saptiani, 2019) keterampilan servis atas dilakukan dengan koordinasi gerak tubuh yang berakhiran dengan gerakan mengayunkan tangan dan juga dibantu dengan kemampuan otot lengan sehingga dapat menciptakan jalannya bola yang cepat, selain itu koordinasi tangan dan mata dapat menyempurnakan arah akurasi bola. Oleh sebab itu servis atas di angap sulit oleh siswa karena membutuhkan akurasi yang sempurna. Secara teori mungkin servis atas itu sulit karena peran servis atas itu sendiri sangat penting untuk menyulitkan lawan dalam menerima bola.

Kesulitan yang dialami siswa pada saat mengikuti servis atas pembelajaran bola voli dapat diketahui dengan masih banyaknya siswa yang tidak semangat dan merasa kesulitan dengan materi servis atas pembelajaran bolah voli, selain itu salah satunya disebabkan tingkat motivasi yang rendah. Menurut (Susanto, Tono, \& Dian, 2019) kesulitan yang sering dihadapi disekolah dalam mengajarkan pembelajaran olahraga adalah motivasi siswa khususnya pada membelajaran bola voli. Menurut (Fauziah, Rosnaningsih, \& Azhar, 2017) siswa yang mempunyai motivasi yang kuat akan berusaha dengan benar mengikuti pembelajaran sedangkan siswa yang tidak mempunyai motivasi akan selalu merasa bosan saat pembelajaran. Motivasi siswa dapat ditingkatkan dengan penggunaan metode pembelajaran yang menarik dan menyenangkan. Metode bermain mampu membuat siswa menjadi lebih antusias, membuat perasaan gembira, senang dan kemauan untuk melaksanakan pembelajaran karena siswa merasakan persaingan dengan temannya (Astuti, 2017).

Kondisi tersebut dapat diatasi apabila guru kreatif dalam proses pembelajaran, agar membuat siswa tertarik terhadap materi servis atas pembelajaran bola voli. tersebut dapat dilaksanakan dengan memberikan metode bermain sebagai cara untuk membuat kesenangan, dan meningkatkan motivasi siswa. Berdasarkan pembahasan tersebut peneliti ingin melakukan penelitian yang bertujuan untuk mengetahui Pengaruh metode bermain terhadap motivasi siswa pada materi servis atas pembelajaran bola voli sekolah menengah pertama karena pada penelitian sebelumnya. Hasil penelitian ini diharapkan dapat menjadi manfaat bagi siswa dalam meningkatkan motivasi karena motivasi merupakan faktor penting dalam pempengaruhi pembelajaran dan diharapkan dapat menjadi acuan bagi guru pendidikan jasmani untuk memperbaiki proses pembelajaran terutama dalam menumbuhkan motivasi siswa. 


\section{Metode Penelitian}

Pendekatan yang digunakan dalam penelitian ini yaitu kuantitatif dan menggunakan metode eksperimen. Tujuan metode eksperimen yaitu mencari pengaruh atau perlakuan terhadap kondisi yang terkendalikan. Metode eskperimen bertujuan untuk mencari pengaruh atau perlakuan terhadap kondisi yang terkendalikan. One Grup Pretest Posttest Design sebagai desain penelitian (Sugiyono, 2017).

Populasi yang digunakan adalah seluruh siswa kelas VIII berjumlah enam kelas sebanyak 215 siswa yang mengikuti materi servis atas pembelajaran bola voli di SMP Negeri 243 Jakarta. Sampel yang digunakan dalam penelitian ini berjumlah 36 siswa. Teknik sampling yang digunakan yaitu cluster random sampling, pemilihan teknik sampling berdasarkan suatu kelompok atau area, misalnya provinsi, desa dan kelas salah satu contohnya. Peneliti mengundi enam kelas untuk ditetapkan sebagai sampel.

Teknik pengumpulan data dalam penelitian ini menggunakan angket. Angket adalah sebuah pertanyaan yang digunakan untuk mengetahui informasi, mengenai fakta atau pendapat (Sari, Sukma \& Indahwati, 2016). Sebelum dibuat pengambilan data penelitian, angket dilakukan uji validitas dan reliabilitas sebagai pengumpul data yang baik. Pengujian dilakukan untuk membuktikan kevalidan dan reliabilitasnya untuk mengatasi pengaruh penggunaan alat ukur, maka peneliti harus menguji penggunaan alat ukur tersebut. Pengambilan keputusan pada uji validitas berdasarkan nilai $\mathrm{r}$ hitung $>$ $r$ tabel dinyatakan item pada alat ukur valid. Berdasarkan hasil uji validitas mengunakan aplikasi SPSS 22 menyatakan dari 36 butir soal terdapat 12 butir soal yang tidak valid dan 24 butir soal yang valid untuk penelitian. Berikut pesebaran alat ukur dalam penelitian ini:

\section{Tabel 1. Sebaran Alat Ukur Penelitian}

\begin{tabular}{llll}
\hline \multirow{2}{*}{ Variabel } & \multirow{2}{*}{ Faktor } & \multicolumn{2}{c}{ Nomor Item } \\
& Fav & Unfav \\
\hline Pengaruh Metode & Motivasi & $1,7,4,5,3,2,6$ & 8 \\
Bermain Terhadap Motivasi Siswa & Instrinsik & $9,13,12,11$ & 10 \\
Pada Materi Servis Atas & & & \\
Pembelajaran Bola & Motivasi & $14,16,15$ & 21 \\
Voli Sekolah Menengah Pertama & Ekstrinsik & $19,18,17$, & 23 \\
& & 20,22 & 24 \\
\hline
\end{tabular}

Menurut (Fajri, 2018) Uji reliabilitas merupakan suatu alat untuk mengukur kuesioner pada penelitian. Jika nilai Cronbach's $\alpha>0,60$ dapat dinyatakan reliabilitas tinggi. Berdasarkan hasil uji reliabilitas menggunakan SPSS 22 mendapatkan hasil Cronbach $\alpha 0,839>0,60$ maka dapat dinyatakan reliabilitas tinggi.

Sebelum dianalisis, data penelitian haruslah berdistribusi normal, tentunya perlu melakukan uji normalitas. Setalah di uji normalitas kemudian data dianalisis dengan uji z menggunakan SPSS 22. Menurut (Santoso, 2018) jika jumlah sampel lebih besar dari 30 uji t digantikan dengan uji z, SPSS 22 tidak menyediakan uji z pada menu analyzenya tetapi uji z bisa dilakukan dengan dengan menggunakan uji t pada SPSS. Hal ini disebabkan pada jumlah sampel yang cukup besar. Cara menafsirkannya dengan mudah mengganti thitung menjadi z hitung pada hasil SPSS tersebut.

\section{Hasil}

Berdasarkan hasil analisis data dapat diketahui perbedaan motivasi siswa antara pretest dan posttest, data dapat dilihat pada tabel berikut: 
Tabel 2. Hasil Motivasi Siswa

\begin{tabular}{lllll}
\hline Data & Jumlah & Rata-rata & Tertinggi & Terendah \\
\hline Pretest & 2079 & 57,75 & 86 & 40 \\
Posttest & 2241 & 62,25 & 92 & 44 \\
\hline
\end{tabular}

Penelitian ini menggunakan uji shapiro wilk sebagai uji normalitas dengan SPSS 22. Menurut (Andi, 2017) Shapiro Wilk merupakan uji normalitas dengan sampel kecil yaitu kurang dari 50 sampel. Data berdistribusi normalnya dilihat dari nilai sig. jika nilai sig. $>0,05$ dinyatakan normal, jika $<0,05$ tidak normal.

Tabel 3. Pengujian Normalitas

\begin{tabular}{lllll}
\hline Data & Statistic & Df & Sig. & Hasil \\
\hline Pretest & .962 & 36 & .253 & Normal \\
Posttest & .963 & 36 & .261 & Normal \\
\hline
\end{tabular}

Berdasarkan tabel 3 di atas, data pretest dinyatakan nilai Sig. sebsar 0,253 > 0,05 dan data posttest 0,261 $>0,05$. Hasil tersebut menunjukan data pretest dan posttest berdisibusi normal.

Setelah uji normalitas memperlihatkan hasil berdistribusi normal. Kemudian dilaksanakan pengujian hipotesis. Hipotesis penelitian ini adalah "diduga terdapat pengaruh metode bermain terhadap motivasi siswa pada materi servis atas pembelajaran bola boli sekolah menengah pertama". Pengujian hipotesis pada penelitian ini menggunakan uji z dengan SPSS 22. Dasar pengambilan keputusan berdasarkan nilai Sig. 2 tailed $<0,05$ dinyatakan Ho diterima, dan jika nilai Sig. 2 tailed $>0,05$ Ho ditolak.

Tabel 4. Pengujian Hipotesis

\begin{tabular}{ccc}
\hline $\boldsymbol{T}$ & $\boldsymbol{D f}$ & Sig. 2 tailed \\
\hline-8.162 & 35 & .000 \\
\hline
\end{tabular}

Berdasarkan tabel diatas Sig. 2 tailed menunjukan hasil $0.000<0,05$. Hasil tersebut menunjukan Ho diterima, dapat dinyatakan terdapat pengaruh signifikan metode bermain terhadap motivasi siswa pada materi servis atas pembelaaran bola voli.

\section{Pembahasan}

Motivasi adalah dorongan atau kekuatan seseorang untuk melakukan kegiatan agar tercapainya tujuan. bagian penting dalam mengikuti pembelajaran disekolah, motivasi sangat menentukan prilaku seseorang terhadap sesuatu yang dilakukannya. Hal ini dapat dikuatkan menurut (Suprihatin, 2015) motivasi merupakan kekuatan seseorang yang menimbulkan tingkat kemauan dalam melaksanakan sesuatu keinginan guna mencapai tujuan. Salah satu tujuan pendidikan jasmani menghasilkan mengembangkan nilai pendidikan pelaksanaanya dengan praktik baik berupa aktivitas jasmani atau bermain yang bersifat pendidik (Gustiawati, 2015). Jika seorang siswa tidak memiliki motivasi dalam mengikuti pembelajaran terlihat menampilkan perasaan yang tidak nyaman dan tidak senang, maka tugas guru sebagai tenaga pendidik harus mengatasi masalah disekolah dengan memberikan metode pembelajaran yang menarik agar membuat siswa bersemangat (Ismaya, 2015). Hal ini didukung juga dengan pernyataan menurut (Permana, 2016) motivasi meningkat apabila guru membangkitkan minat siswa, rasa ingin tahu mereka, menggunakan berbagai macam metode pembelajaran yang menyenangkan.

Metode bermain adalah bentuk kegiatan bermain yang digunakan untuk menyampaikan pembelajaran kepada siswa. Bermain merupakan suatu aktivitas yang sangat disenangi siswa, karena pada saat jam istirahat atau sebelum dan sesudah jam pelajaran hampir seluruh siswa asyik bermain dengan 
temannya. Bermain yang dimaksud disini bukan sekedar bermain untuk bersenang-senang tapi jenis permainan yang diberikan bertujuan untuk tercapai tujuan pembelajaran pendidikan jasmani. Permainan yang digunakan juga harus disesuaikan dengan karakteristik siswa, lingkungan sekolah dan media pembelajaran disekolah. (Hambali, 2016) berpendapat berbagai cara dalam pelaksanaan pembelajaran harus dikemas menjadi permainan yang menyenangkan agar seluruh siswa merasakan senang dan gembira saat proses pembelajaran. Dalam permainan yang diberikan tidak menekankan kepada teknik atau prestasi olahraga melainkan penguasaan gerak dasar atau bagaimana seorang siswa dapat melakukan gerakan dasar dengan benar dan kodirnasi yang baik. Khususnya pada siswa sekolah menengah pertama rasa senang akibat bermain merupakan bagian utama untuk menimbulkan situasi yang menyenangkan serta meningkatkan motivasi siswa terhadap pembelajaran (Hambali \& Sutiwo, 2019). Sebab pada siswa sekolah pertama bermain adalah modal utama untuk menarik perhatian mereka dalam melaksanakan kegiatan, terutama pada pembelajaran bola voli.

Penggunaan metode bermain dapat memperbaiki proses pembelajaran pendidikan jasmani khususnya pada materi servis atas pembelajaran bola voli, dan dapat meningkatkan motivasi siswa pada pembelajaran (Zulfiyantono \& Hidayat, 2018). Metode bermain bermain dapat meningkatkan fisik khususnya power otot tungkai atlit bola voli karena dengan permaianan akan merasa gembira, gembira dan merasa tidak tertekan saat proses latihan (Junaidi, 2019). Metode bermain dapat menghilangkan rasa jenuh pada anak, kegiatan pembelajaran tanpa tekanan membuat pembelajaran penuh gembira, menyenangkan dan menghasilkan kepuasan, hubungan antar siswa, selain hal tersebuh juga dapat meningkatkan kemampuan servis atas (Kasriadi \& Irawan, 2019).

Metode pembelajaran dapat meningkatkan kemampuan servis atas pembelajaran bola voli salah satunya metode bermain, Metode bermain memiliki ciri khusus untuk meningkatkan hasil belajar servis atas pembelajaran bola voli (Sanur, 2016). Metode bermain dapat memberikan peningkatan yang positif terhadap minat siswa, minat adalah suber motivasi yang dapat mengarahkan siswa kepada apa yang ingin dilakukannya jika diberi kebebasan (Idaman \& Hartati, 2015). Berdasarkan hasil penelitian ini metode bermain berpengaruh terhadap motivasi siswa dikarenakan dengan permainan membuat siswa senang dan bersemnagat dalam mengikuti pembelajaran. Hal ini sesuai yang dijelaskan (Anam \& Muhammad Nur, 2019) metode bermain dapat membuat siswa termotivasi karena siswa menyukai permainan yang diberikan.

Berbeda dengan penelitian di SMPLB-B Dharma Asih Pontianak oleh (Riswono, 2018) bahwa metode bermain tidak menunjukan pengaruh yang singnifikan terhadap motivasi belajar hal tersebut disebabkan karena terjadi hambatan pada waktu yang diperlukan untuk belajar sehingga perlu pengolaan waktu yang baik. Penelitian (Nurlatifah, Subarjah, \& Supriyadi, 2018) menyatakan bahwa penerapan metode bermain dalam pembelajaran pendidikan jasmani memiliki peningkatan terhadap motivasi siswa tak lain karena siswa yang tidak merasa bosan dengan permainan yang diberikan sehingga menarik rasa penasaran siswa sehingga mereka tertarik mengikuti pembelajaran dengan tertib.

\section{Simpulan dan Rekomendasi}

Berdasarkan hasil analisis data statistik dan uji hipotesis maka dapat ditarik kesimpulan "terdapat pengaruh metode bermain terhadap motivasi siswa pada materi servis atas pembelajaran bola voli sekolah menengah pertama". Materi servis atas pembelajaran bola voli dengan menggunakan metode bermain ternyata mampu meningkatkan motivasi siswa.

Rekomendasi yang dapat peneliti berikan adalah diperlukan penelitian lanjutan tentang metode pembelajaran lain yang mungkin mempunyai pengaruh terhadap motivasi siswa pada materi servis atas pembelajaran bola voli dan dapat dilakukan penelitian lanjutan kearah guru, masyarakat, dan atlet dengan menggunakan metode bermain untuk mengkaji motivasi terhadap sesuatu hal. 


\section{Daftar Pustaka:}

Anam, K., \& Muhammad Nur, H. (2019). Pengaruh Metode Bermain Terhadap Kemampuan Motorik Siswa Kelas Viii Di Smp Negeri 21 Surabaya. Jurnal Pendidikan Olahraga Dan Kesehatan, 7(2), 363367.

Andi. (2017). Ragam Model Penelitian dan Pengolahannya Dengan SPSS. Semarang: Wahana Komputer.

Astuti, Y. (2017). Pengaruh Metode Drill dan Metode Bermain Terhadap Keterampilan Bermain Bola Voli Mini. Al Ibtida: Jurnal Pendidiken Guru MI. https://doi.org/10.24235/al.ibtida.snj.v4i1.1276

Efendi, R. (2017). Sosiologi Olahraga. Karawang: Ristek Dikti.

Fajri, M. (2018). Hubungan Antara Motivasi Belajar Dengan Prestasi Belajar Peserta Didik Pada MAta Pelajaran Penjaskes Kelas X di SMA Sekolah Rakyat Babelan - Bekasi. GENTA MULIA, IX(2), 93-106.

Fauziah, A., Rosnaningsih, A., \& Azhar, S. (2017). HUBUNGAN ANTARA MOTIVASI BELAJAR DENGAN MINAT BELAJAR SISWA KELAS IV SDN PORIS GAGA 05 KOTA TANGERANG. Jurnal JPSD (Jurnal Pendidikan Sekolah Dasar). https://doi.org/10.26555/jpsd.v4i1.a9594

Gustiawati, R. (2015). Evaluasi pembelajaran pendidikan jasmani (Winarni, Ed.). Bandung: Multi Kreasindo.

Hambali, S. (2016). PEMBELAJARAN PASSING BAWAH MENGGUNAKAN METODE BERMAIN PADA PERMAINAN BOLA VOLI. Jurnal Pendidikan Olahraga, 5(1), 58-70.

Hambali, S., \& Sutiwo. (2019). Pengaruh metode bermain terhadap hasil belajar passing bawah bola voli di sekolah dasar. Perspektif Ilmu Pendidikan, 33(1), 27-32. https://doi.org/http://doi.org/PIP.331.3

Hanggara, D. (2018). IMPLEMENTASI EKSTRAKURIKULER BOLA VOLI DI SMA N 1, 2 DAN 3 BENGKULU TENGAH. Jurnal Ilmiah Pendidikan Jasmani,2 (1) 2018., 2(1), 16-22.

Idaman, N., \& Hartati, S. C. Y. (2015). Penerapan metode bermain terhadap minat siswa dalam pembelajaran pendidikan jasmani olahraga dan kesehatan. 03, 462-472.

Ismaya, B. (2015). Pengelolaan pendidikan (N. F. Atif, Ed.). Bandung: PT. Refika aditama.

Junaidi, S. (2019). METODE LATIHAN BERMAIN UNTUK MENINGKATKAN POWER OTOT TUNGKAI ATLET BOLAVOLI PADA TIM PERVIK KEDIRI TAHUN 2018. 2(1).

Kasriadi, E., \& Irawan, R. (2019). Modifikasi bentuk bermain berpengaruh terhadap servis atas bola volo. Jurnal Patriot, 1(3), 1053-1063.

La'I, R. A., \& Haluti, A. (2018). Pelatihan Teknik Dasar Permainan Bola Voli. MONSU'ANI TANO : Jurnal Pengabdian Masyarakat, 1(1). https://doi.org/10.32529/tano.v1i1.245

Nurlatifah, W., Subarjah, H., \& Supriyadi, T. (2018). Pengaruh Metode Bermain Terhadap Motivasi Belajar Siswa Dalam Pendidikan Jasmani. SpoRTIVE, 1(1), 181-190.

Pahliwandari, R. (2016). Penerapan Teori Pembelajaran Kognitif dalam Pembelajaran Pendidikan Jasmani dan Kesehatan. Jurnal Pendidikean Olabraga, 5(2), 154-164.

Permana, A. (2016). Pengaruh Gaya Belajar dan Motivasi Belajar Mahasiswa Terhadap Kemampuan Belajar Ilmu Alamiah Dasar. Formatif: Jurnal Ilmiah Pendidikan MIPA. https://doi.org/10.30998/formatif.v6i3.999

Rahayu, E. T. (2016). Strategi pembelajaran pendidikan jasmani. Bandung: Alfabeta.

Riswono, D. (2018). PENGARUH PENDEKATAN BERMAIN TERHADAP MOTIVASI BELAJAR PENJASORKES DI SMPLB-B DHARMA ASIH PONTIANAK. Pendidikan Dan 


\section{Pembelajaran Khatulistiwa, 7(5).}

Santoso, S. (2018). Menguasai SPSS 22. Jakarta: PT. Elex Media Komputindo.

Sanur. (2016). Upaya Meningkatkan Hasil Belajar Servis Atas Permainan Bola Voli Dengan Pendekatan Bermain Pada Siswa Kelas VI SDN Batokerbuy 2 Tahun Ajaran 2015/2016. Jurnal Sportif, 2(1), 93. https://doi.org/10.29407/js_unpgri.v2i1.660

Saptiani, D. (2019). Hubungan kekuatan koordinasi mata tangan dan otot lengan terhadap akurasi servis atas bola voli pada peserta putri ekstrakurikuler di sman 2 seluma. Jumal Ilmiah Pendidikan Jasmani, 3(1).

Sari, Sukma, D., \& Indahwati, N. (2016). HUBUNGAN KEMAMPUAN MOTORIK DAN MOTIVASI BELAJAR TERHADAP HASIL BELAJAR PENDIDIKAN JASMANI,OLAH RAGA DAN KESEHATAN. Jurnal Pendidikan Olabraga Dan Kesehatan Volume 04 Nomor 03 Tahun 2016, 556 - 563 HUBUNGAN, 04, 556-563.

Sugiyono. (2017). Metode penelitian kualitatif, kuantitatif dan R\&D. Bandung: Alfabeta.

Suprihatin, S. (2015). UPAYA GURU DALAM MENINGKATKAN MOTIVASI BELAJAR SISWA. JURNAL PROMOSI Jurnal Pendidikan Ekonomi UM Metro Kondisi, 3(1), 73-82.

Susanto, T., Tono, S., \& Dian, P. (2019). Upaya meningkatkan kemampuas servis atas melalui penerapan latihan menggunakan dumbbell pada siswa kelas X IPS 6. Jurnal Ilmiah Pendidikan Jasmani, 3(1), 125-132.

Syaleh, M. (2017). UPAYA MENINGKATKAN HASIL BELAJAR SERVIS ATAS BOLA VOLI MELALUI MEDIA PEMBELAJARAN LEMPAR PUKUL BOLA KERTAS PADA SISWA KELAS VII SMP. JURNAL PRESTASI. https://doi.org/10.24114/jp.v1i1.6494

Zulfiyantono, sulaiman ismun haq, \& Hidayat, T. (2018). Pengaruh metode bermain terhadap hasil belajar servis atas bola voli. Jurnal Pendidikan Olahraga Dan Kesehatan, 06, 423-431. 